\title{
Virtual Researcher on Call: encouraging the youth of today to become the researchers of tomorrow
}

\section{Kevin Cougler}

Kevin Cougler, "Virtual Researcher on Call: encouraging the youth of today to become the researchers of tomorrow," Proc. SPIE 9665, Tenth International Topical Meeting on Education and Training in Optics and Photonics, $96651 \mathrm{Z}$ (3 June 2007); doi: 10.1117/12.2207810

SDIE Event: Tenth International Topical Meeting on Education and Training in Optics and Photonics, 2007, Ottawa, Ontario, Canada 


\section{Virtual Researcher on Call: "Encouraging the youth of today to become the researchers of tomorrow" Kevin Cougler et al VROC - Virtual Researcher On Call London, Ontario Canada}

Virtual Researcher On Call (VROC) is an educational initiative of Partners In Research and was created as an opportunity to connect current research and researchers with high school students in grades 9 to 12 throughout Canada. The concept was to use a web-based interface to optimize time requirements for this connection through the use of videoconferencing technology. In addition, this program was thought to match the opportunity for researchers to explain and showcase their work, interact with students who may potentially become the next generation of researchers and to increase the knowledge of the general public about the advances being made by Canadian Researchers and the benefits to the Canadian Society, and by extension to the world at large.

For the Teachers, this program is a resource to enhance their curriculum content and also for them to see first hand, information that would not be available in text books, sometimes until years later. For the students, it was expected that this would be a rare opportunity not only to hear about new developments but for them individually to have dialogue with researchers who are involved in these new discoveries. For some this would be an opportunity to have some insight into what they were considering for a career choice. Indeed, it might lead to mentorship or even an opportunity for a job placement in a laboratory. For some students, it might provide information to assist them in deciding general areas of their schooling that they might pursue, and for others it might provide a rationale for them to finish their high school career. 